\title{
Informal Learning Recognition and Management
}

\author{
David Griffiths \\ Educational Cybernetics \\ School of Education and Psychology \\ The University of Bolton \\ d.e.griffiths@bolton.ac.uk
}

Francisco José García Peñalvo

GRIAL Research Group

Research Institute for Education Sciences

Computer Science Department

The University of Salamanca

fgarcia@usal.es

The papers in this special issue were conceived as a response to the problem of transferring knowledge and experiences from informal to formal learning contexts. It is easy to see why a solution to this problem would be desirable. There is a widespread consensus in policy that an effective formal education system is a key factor in achieving economic success. At a personal level, the formal education system is seen enables those who successfully complete their studies to achieve a better life for themselves, as documented by the OECD (2011-2015), and for higher education, by the British Department for Business Innovation and Skills (2013). A report published by the European Union on the macroeconomic benefits of vocational education concludes that "economic success depends on the availability of skills developed ... both in general and vocational education." (CEDEFOP, 2015, p.1), while for low income countries it has been confirmed that for low income countries "the widely held belief that investing in education and skills promotes economic growth ... is correct overall" (Hawkes and Ugur, 2012, p.5).

But, despite the dramatic and continuing growth of the education system, there are many areas of learning which lie beyond its reach. Many of the capabilities which lead to success in a career are not learned during schooling or higher education, but rather in informal activities in the home, in social interaction, in interaction with media and in the course of work (see Dufura, Parcel, and Troutman (2013) for an argument that variation in home environment has a greater influence on academic success than variation in schooling, and De Grip (2015) for a recent review of the importance of informal learning at the workplace). It is an attractive proposal to suggest that these informal activities could be harnessed to strengthen the education system, and that some of the methods of formal education would be applied to increase the effectiveness of informal learning. Agencies and policymaker institutions, such as the European Union have supported initiatives with these goals. The European Commission Council Recommendation of 20th December 2012 declared:

The validation of learning outcomes, namely knowledge, skills and competences acquired through non-formal and informal learning can play an important role in enhancing employability and mobility, as well as increasing motivation for lifelong learning, particularly in the case of the socioeconomically disadvantaged or the low-qualified" (The Council of the European Union, 2012, p.1). Similarly some teachers were keen to introduce informal learning into the activities they carried out with learners.

Unfortunately, the results of this work confirm the judgement of Werquin, formerly Senior Economist of the OECD, that

recognition of non-formal and informal learning is high on many countries' agenda. These systems, despite being rather convincing in theory, seem to have trouble taking off and reaching cruising speed. On the positive side, there is room for recognition systems and there are islands of good practice. On the negative side, there is little evidence that these systems work, and they seem to be mostly based on faith (Werquin, 2008, p.7).

It seems that the transfer of knowledge and experiences between formal and informal contexts, is an enticing proposition which has proved much more challenging to realise than had been expected, and we believe that a great deal of good work has been done to achieve this transfer. From a personal perspective, both the editors of this present issue were involved in the TRAILER project (García-Peñalvo et al., 2013), funded by the European Commission, which proposed an infrastructure for gathering evidence of informal learning and 
making it available to workers and managers (García-Peñalvo, Johnson, et al., 2014; García-Peñalvo \& Conde, 2014). We therefore believe that an explanation which focuses on the shortcomings of efforts to resolve the problem is not convincing. Rather we are led to conclude that the gap to be bridged between formal and informal contexts is a great deal wider and deeper than had been assumed (García-Peñalvo, Colomo-Palacios \& Lytras, 2012).

In designing systems for the validation of informal learning, or for incorporating aspects of informal learning in formal education, there is an underlying assumption that formal and informal learning take place in separate domains, and that a clear line can be demarcated between them, in both theory and practice. Following a line of argument which we have put forward elsewhere (García-Peñalvo, Griffiths et al., 2014), this is problematic, for two reasons.

Firstly, the criteria for 'formality' are not self evident. The word itself is used in a number of ways which are related to education, but are not concerned with distinguishing between the structures of educational activities. Formal language for example, is related to modes of expression and presentation which would be perfectly admissible in informal learning interactions. The term formal is also associated with knowledge. The Encyclopedia of Decision Making and Decision Support Technologies (Adam \& Humphreys, 2015) reveals the contradiction by providing two definitions of formal knowledge:

1. Information made explicit and associated with a semantic meaning...

2. Knowledge and information created and shared by formal institutions and their representatives... This can lead to confusion, particularly in cases of structured knowledge which the curricula established by educational institutions may classify as trivial, for example the classification of Hip Hop by Piskor (2014). Nor are educational methods exempt from doubt about their formality. Socrates' dialogues were a formal educational method as regards their use of logic, but informal in that they were unplanned, and could take place anywhere. Medieval education also had many of formal aspects that Socratic dialogue lacked, with the main activity being the study of set texts, in specified locations and with much ceremony. But these activities did not have the clearly articulated pedagogy of the Socratic dialogue, nor the objectives and assessments which we would now think of as characterising formal education. To resolve this uncertainty we propose that formality in education be seen not a function of the materials studied, nor of the pedagogic methods adopted, but rather as indicating the degree to which the learning process is managed by an educational institution or authority. This proposal may not be universally accepted in full, but it seems uncontroversial that the use of the instruments of educational management (curricula, assessments, qualifications, etc.) is, at least, an important indicator of the formality of learning. However, even if the above proposal is accepted, a second problem of demarcation arises, which is more intractable than that of confused definitions, as we now discuss. As Wiener pointed out many years ago, in the social sciences in general "the observer is able to exert a considerable influence on the phenomena that come to his attention" (Wiener, 1948 p. 162). However, not only do educational researchers investigating the relationship of informal and formahlearning 'exert a considerable influence' on the object of their study, it can be argued that they transform the object of their study through their own activities. In order to bring informal learning achievements into the domain of formal education, formal methods must be applied, which have the effect of formalising the informal learning which they set out to study. Similarly, informal learning activities carried out by an individual at their own initiative offer a different experience to the learner when compared with the same activities when adopted by a teacher as part of a course. The activities or tools which are adopted may well improve the course (Conde et al., 2014), but this will not of itself change the formal nature of the course.

From this perspective outlined above, it may be seen that the task undertaken by this special issue (investigating the transfer of knowledge and experiences from informal to formal learning contexts) is reflexive, and, consequently extremely complex. This complexity does not mean, however, that it is a hopeless undertaking; rather it explains why the problem has been resistant to solution. Despite the difficulties we can hope for insight into, among other things:

- Ways that formal education can renew itself from contact with informal education

- Methods which enable formal education to extend its reach to aspects of learner activity which are currently beyond its reach, and studies

- Methods for enhancing the environment and processes of informal learning, without seeking to formalise them.

The papers in this special address these points in the following ways.

Firstly, three papers focus primarily on bringing informal practices to formal education. Fonseca, Valls, Redondo and Villagrasa examine how a course in architecture and urban design was enriched with feedback in an informal environment from end users, with a positive impact on student's skills. Sánchez-Prieto, 
Olmos-Migueláñez and García-Peñalvo analyse the relationship between teachers' intentions and the expanding use of mobile technology in informal learning. González et al. describe a successful intervention which uses gaming methods from informal contexts, as an alternative to traditional pedagogic interventions which address obesity.

Secondly, two papers which use technology to analyse learners activities, and so extend the reach of formal learning methods to cover areas which are presently ignored and/or handled informally. Hung, Chang and Lin propose that learning performance in problem solving tasks is related to the preferred learning styles of learners, a factor which pedagogy normally leaves to chance or intuition, and propose a data mining technique to manage the relationship. Similarly, Belcadhi proposes that technology can be used to provide personalised feedback to learners in a way which is often not available in formal education.

Thirdly, three papers reveal patterns of interaction that can enhance informal learning. Pata, Santos and Burchert analyse professional discussion forums to identify a set of interrelated patterns that are used for socially verifying and maturing rules and guidelines, solving problems, introducing new practices and triggering learning. They discuss how these could be used to enhance the quality of informal learning in the workplace. Aramo-Immonen et al. also analyse the data generated by social media, in this case Twitter. They show how the Ostinato Model, which they introduce in this paper, can use this data to construct an informal learning environment around a conference. Galanis et al. offer a framework which provides mechanisms for personalised recommendations for informal learning opportunities, by analysing peer interaction and peer assessment rather than relying on the judgment of experts.

\section{Acknowledgements}

We would like to thank the staff of Computers in Human Behavior, and the Editor-in-Chief, Dr. Robert Tennyson, for the support which we have received in preparing this special issue. Our thanks also go to the authors of the selected papers for their assiduous work in writing and refining their papers. Finally, we would like to express our gratitude to the reviewers of these articles, whose work is a largely invisible but essential part of the process. It has been a pleasure to collaborate with you all.

\section{References}

Adam, F., \& Humphreys, P. (eds.), (2008). What is formal knowledge? In Encyclopedia of Decision Making and Decision Support Technologies (2 Volumes). IGI. Retrieved September 23, 2015, from $\mathrm{http}: / / \mathrm{www}$.igi-global.com/dictionary/formal-knowledge/11382

CEDEFOP. (2014). Macroeconomic benefits of vocational education and training (p. 96). Luxembourg.

Conde, M. Á., García-Peñalvø, F. J., Rodríguez-Conde, M. J., Alier, M., Casany, M. J., \& Piguillem, J. (2014). An evolving Learning Management System for new educational environments using 2.0 tools. Interactive Learning Environments, 22(2), 188-204. doi:10.1080/10494820.2012.745433

De Grip, A. (2015). The importance of informal learning at work. IZA World of Labor, (June), 1-10. doi:10.15185/izawol.162

Department for Business Innovation \& Skills. (2013). The Benefits of Higher Education Participation for Individuals and Society: key findings and reports "The Quadrants" (p. 51). Retrieved from https://www.gov.uk/government/publications/benefits-of-participating-in-higher-education-key-findingsand-reports-quadrants

Dufura, M. J., Parcel, T. L., \& Troutman, K. P. (2013). Does capital at home matter more than capital at school? Social capital effects on academic achievement. Research in Social Stratification and Mobility, $31,1-21$.

García-Peñalvo, F. J., Colomo-Palacios, R., \& Lytras, M. D. (2012). Informal learning in work environments: training with the Social Web in the workplace. Behaviour \& Information Technology, 31(8), 753-755. doi:10.1080/0144929X.2012.661548

García-Peñalvo, F. J., \& Conde, M. Á. (2014). Using informal learning for business decision making and knowledge management. Journal of Business Research, 67(5), 686-691. doi:http://dx.doi.org/10.1016/j.jbusres.2013.11.028

García-Peñalvo, F. J., Conde, M. Á., Zangrando, V., García-Holgado, A., Seoane, A. M., Forment, M. A., . . . Minović, M. (2013). TRAILER project (Tagging, recognition, acknowledgment of informal learning experiences). A Methodology to make visible learners' informal learning activities to the institutions. Journal of Universal Computer Science, 19(11), 1661. doi:10.3217/jucs-019-11-1661

García-Peñalvo, F. J., Griffiths, D., Johnson, M., Sharples, P., \& Sherlock, D. (2014). Problems and opportunities in the use of technology to manage informal learning. In In Proceedings of the Second 
International Conference on Technological Ecosystems for Enhancing Multiculturality (TEEM '14) (pp. 573-580). New York, NY, USA: ACM. doi:10.1145/2669711.2669958

García-Peñalvo, F. J., Johnson, M., Ribeiro Alves, G., Minovic, M., \& Conde-González, M. Á. (2014). Informal learning recognition through a cloud ecosystem. Future Generation Computer Systems, 32, 282294. doi:http://dx.doi.org/10.1016/j.future.2013.08.004

Hawkes, D., \& Ugur, M. (2012). Evidence on the relationship between education, skills and economic growth in low-income countries: A systematic review. London: EPPI-Centre, Social Science Research Unit, Institute of Education, University of London.

OECD. (2011-2015). Better Life Index: Education. Retrieved September 23, 2015, from http://www.oecdbetterlifeindex.org/topics/education/

Piskor, E. (2014) Hip Hop Family Tree 1975-1983 Gift Box Set Paperback, Fantagraphics, Seattle WA.

The Council of the European Union. (2012). Council Recommendation of 20th December 2012 on the validation of non-formal and informal Learning. Official Journal of the European Union, 398(1), 1-6.

Werquin, P. (2008). Recognition of non-formal and informal learning in OECD countries: A very good idea in jeopardy? Lifelong Learning in Europe 2008, 3, 42-49.

Wiener, N., Cybernetics, or Control and Communication in the Animal and the Machine, MIT Press, Cambridge, M, 1948/1961

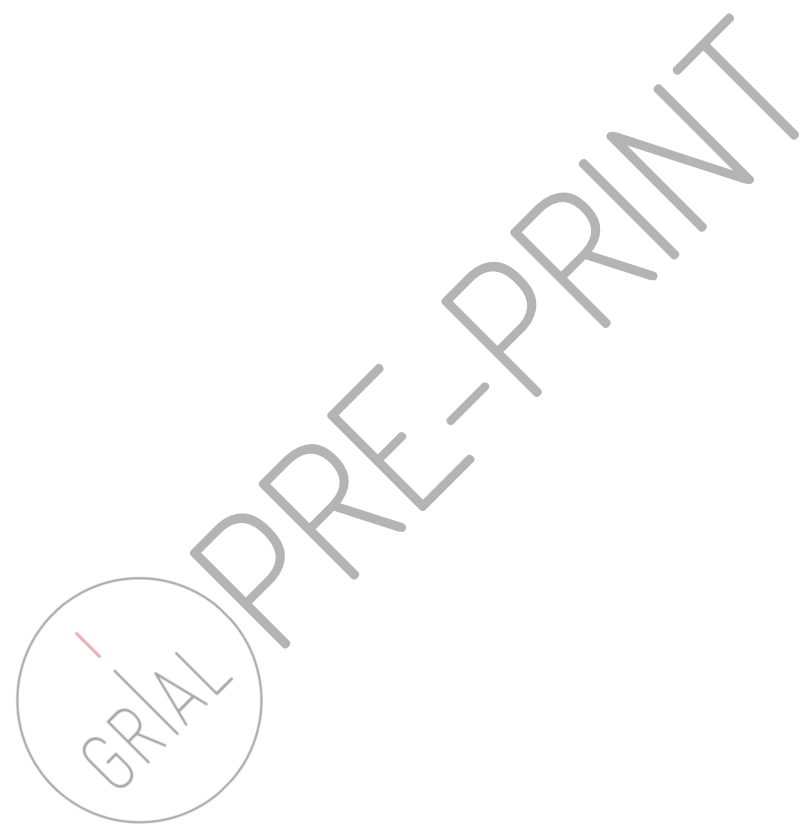

